\title{
Erratum
}

\section{Erratum to: Reputation at Risk: The Social Responsibility of NGOs}

\author{
A Critical View of Post-communist Environmental NGO Impact
}

\author{
Paul A. Argenti \\ The Tuck School of Business at Dartmouth, 100 Tuck Drive, \\ Hanover, NH 03755, USA \\ E-mail: Paul.A.Argenti@tuck.dartmouth.edu
}

\author{
Anna Saghabalyan \\ “Lydian Armenia” CJSC, Vazgen Sargsyan 26/1, 0010 Yerevan, \\ Armenia \\ E-mail: a.saghabalyan@gmail.com
}

Corporate Reputation Review (2017) 20, 123-124. doi:10.1057/s41299-017-0019-2;

published online 11 April 2017

\section{ERRATUM TO: CORPORATE REPUTATION REVIEW (2017) DOI 10.1057/S41299-017-0013-8}

The publisher would like to apologise that Fig. 1's inclusion and Fig. 2's label and citation were omitted at the time of online publication. The article has been corrected as of 5 April 2017 and Figure 1 has been included after the sentence:

In cases and literature observed earlier we saw several commonalities of inefficiency of NGOs (Fig. 1).
Figure 2 has been cited after the sentence: However, the hypothetical framework (II) may lead to strong partnerships between western-funded NGOs and investors that may challenge government inefficiency and lead to institutional change (Fig. 2).

And a label has been added to the figure which is shown on the following page.

No other element of the article has been amended and no other element of the article is under question. 
Fig. 1: Common Shortcomings of NGOs
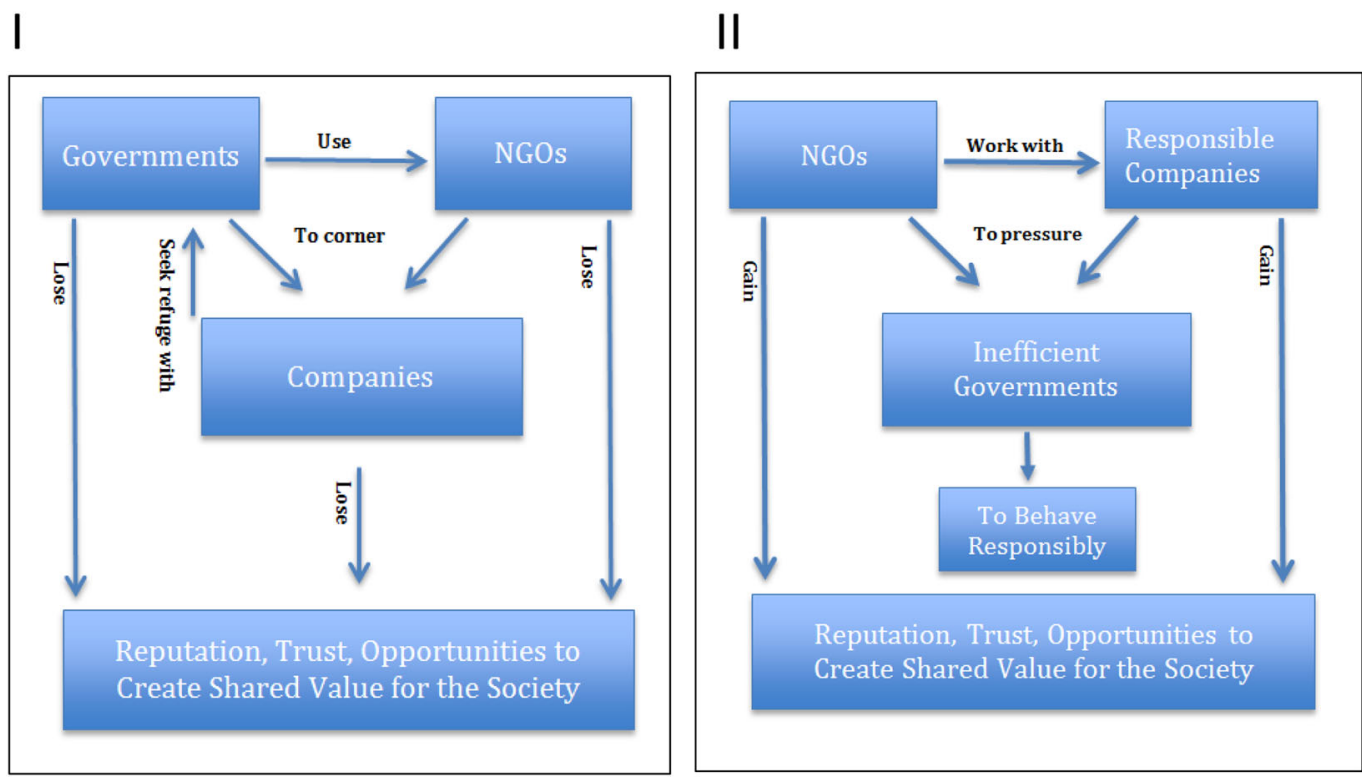

Fig. 2: I) Common NGO-Business-Government Interaction and Consequences II) Suggested Change of Behavior and Possible Benefits 